\title{
DEVELOPMENT OF NEW AIRBORNE LASER SCANNING METHOD BY MEANDERING FLIGHT
}

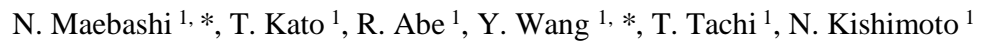 \\ ${ }^{1}$ Geospatial Technology Department, Kokusai Kogyo Co., Ltd., 2-24-1 Harumi-cho, Fuchu, Tokyo 183-0057, Japan - \\ (naoya_maebashi , takayuki_kato, ryogo_abe, a_o, tomoe_tachi, natsuko_kishimoto)@kk-grp.jp
}

Commission I, WG I/2

KEY WORDS: Airborne LiDAR, Helicopter, Meandering flight, Laser analysis method

\begin{abstract}
:
Japan has many meandering rivers in her mountainous areas. Many hazards have occurred in their surroundings. Airborne laser scanning (ALS) is one of measures for disaster prevention in the surrounding of a meandering river. In Japan, ordinary ALS by using both a fixed wing airplane and a rotary wing airplane adopts flying along straight lines over a target area. Although ALS along straight lines is effective when a target area is planar, ALS along straight lines for a meandering river in a mountainous area increases the number of flying courses and flight time. On the other hand, although ALS by a meandering flight along a target meandering river would be efficient in data acquisition, it depends on the skill of a pilot and brings difficulty in data processing to secure measuring accuracy. We decided to develop a new efficient ALS method by a meandering flight. It systematizes flight planning, GCP allocation, and data processing especially course adjustment to secure required measuring accuracy. After conducting preliminary experiments in the test area, measuring accuracy was verified following the operation guidelines for the Japanese public surveying established by the Ministry of Land, Infrastructure, Transport and Tourism of Japan. The result that the accuracy by a meandering flight would be almost the same as that by a straight-line flight, and indicated that it would meet the operation guidelines for Japanese public surveying.
\end{abstract}

\section{INTRODUCTION}

In the last decade, Japan has several large-scale disasters. On March 11, 2011 an extremely huge earthquake, which was later named the Great East Japan Earthquake, occurred. Since March of 2011, we had three huge earthquakes: two earthquakes in Kumamoto in April of 2016 and one earthquake in Hokkaido in September of 2018. In recent years, storms and floods such as river flooding due to typhoons and torrential downpours are occurring frequently and becoming even more severe. Figure 1 shows a river flooding due torrential downpours in Fukuoka on June, 2017.

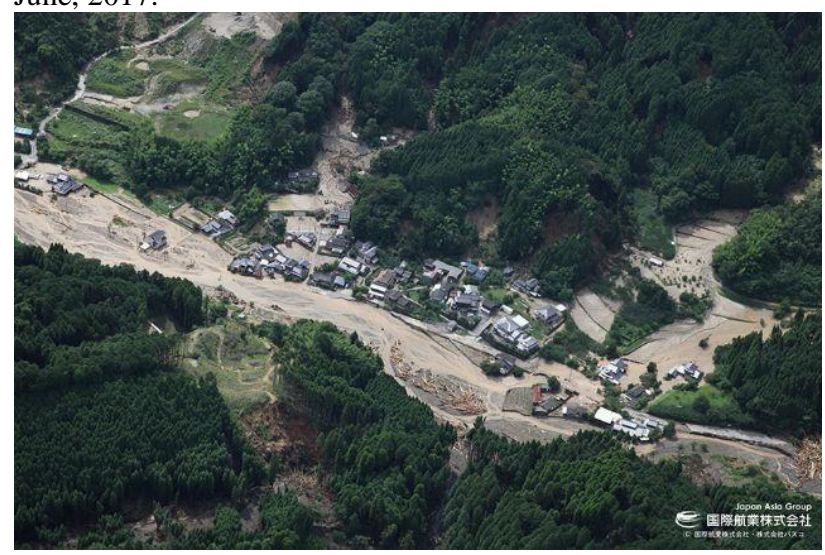

Figure 1. River flooding due torrential downpours
For pre-disaster prevention and quick recovery from large-scale disasters, the Japanese Government established the Basic Act for National Resilience Contributing to Preventing and Mitigating Disasters for Developing Resilience in the Lives of the Citizenry in 2013. Moreover, the Government has formulated Three-Year Emergency Measures for Increasing the Resilience of the National Territory (2019-2021) as a measure against intensifying disasters. The national measures adopt the most advanced surveying technologies as an effective measure, and these are utilized corresponding to the stages: (1) prior disaster prevention, (2) emergency measures in the event of a disaster, (3) restoration and reconstruction measures, and so on.

The Ministry of Land, Infrastructure, Transport and Tourism of Japan is now working on a number of measures for pre-disaster prevention and quick recovery. Airborne laser scanning (ALS) is one of the measures. ALS is effective for not only pre-disaster prevention but also grasping situation after a disaster.

Japan is a small and mountainous country. Channel extensions of most rivers in Japan are short and their longitudinal bed slopes are steep. Upper reaches of many rivers in Japan locate in steep mountainous areas, and most of the rivers meander among mountains. Disasters such as river flooding and landslides have occurred in the surroundings of a meandering river.

ALS has been utilized for river management (Yoshida et al., 2017) and slope failure survey (Hiramatsu et al., 2017) in Japan.

* Corresponding author 
Ordinary ALS is used with both fixed wing and rotary wing airplane flying along straight lines over a target area. ALS along straight lines is effective when the target area is planar, since the target area and survey area match. However ALS in straight lines for a meandering area (e.g. rivers, roads, etc.) the number of flying courses and flight time will increase compared to flying the same area in a planar measurement leading to inefficiency. Conducting ALS along a meandering feature with meandering flight would be efficient for data acquisition. Nevertheless, since issues exist regarding pilot skills and data measurement accuracy, there have been few reports focusing on ALS by a meandering flight. Accordingly, we decided to develop a new efficient ALS analysis method for meandering flights. It should systematize flight planning, GCP allocation, and data processing for course adjustment to secure the required measuring accuracy. We conducted two experiments. One is a preliminary experiment to investigate possibility of ALS by a meandering flight, and the other is a practical experiment to investigate feasibility of adopting ALS by a meandering flight in Japanese public surveying. This paper reports the experiments conducted for development of a new efficient ALS method by a meandering flight.

\section{PRELIMINARY EXPERIMENT}

\subsection{Outline of the preliminary experiment}

We conducted a preliminary experiment to investigate possibility of ALS by a meandering flight at the upper reaches of Tama River, which is one of Japanese Class A rivers, in Ome City, Tokyo Metropolis. Figure 2 shows the target area. The target area is an area surrounded by 400 -meter-high mountains on both sides of the river.

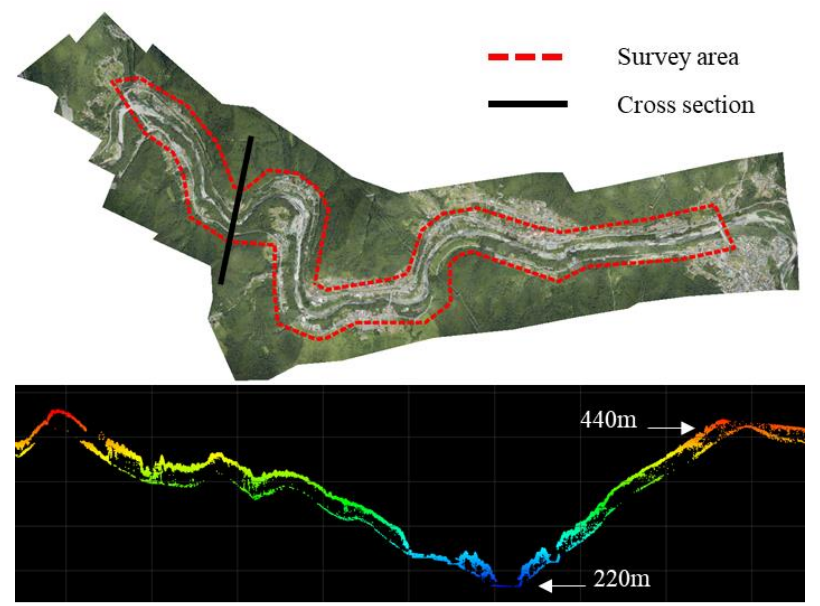

Figure 2. Target area of the preliminary experiment

We used a Leica Chiroptera II in the experiment. Table 1 shows the specifications of Chiroptera II. Chiroptera II has two observation modes: one is the topographic mode by using infrared laser, and the other is the bathymetric mode by using green laser. We executed data acquisition by using the topographic mode. Since a meandering flight by fixed wing airplane is difficult, we adopted a helicopter (Aerospatiale AS350) as a platform in the preliminary experiment.

We conducted two sets of observation on June 25, 2018. One was conducted by a flight along straight lines and the other was conducted by a flight along a meandering river as Figure 3 shows. Table 2 shows the LiDAR surveying specifications of the flights.

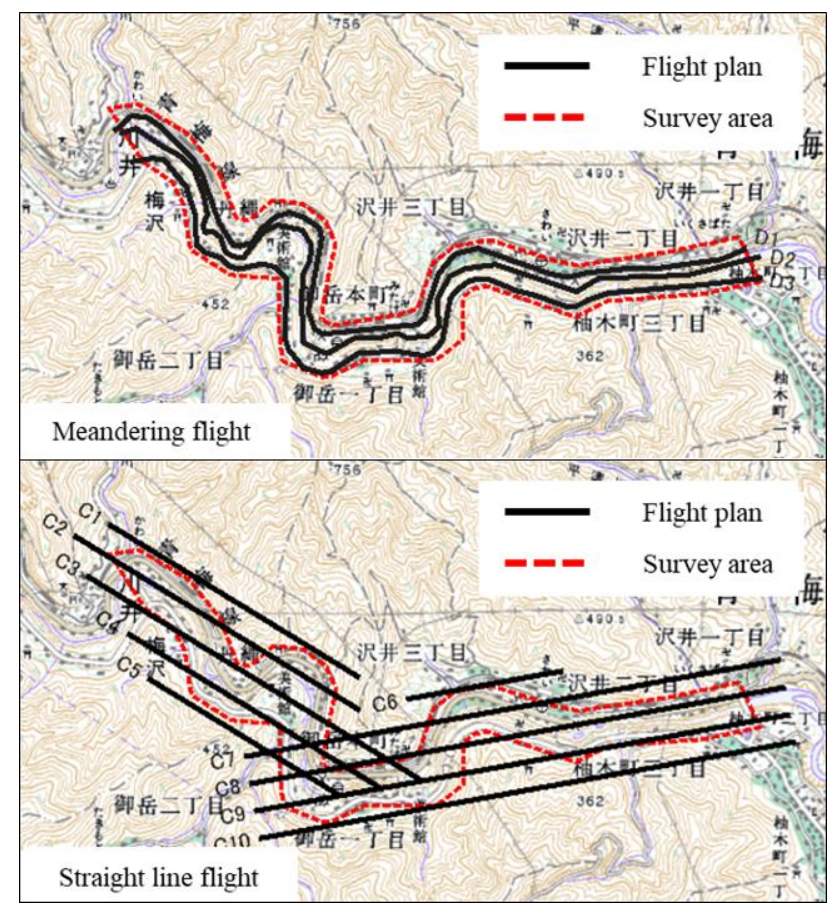

Figure 3. Flight plan of the preliminary experiment

\begin{tabular}{|c|c|c|}
\hline \multirow{2}{*}{} & \multicolumn{2}{|c|}{ Chiroptera II } \\
\cline { 2 - 3 } & Topographic & Bathymetric \\
\hline Laser wavelength & Infrared (1064nm) & Green $(532 \mathrm{~nm})$ \\
\hline Laser range & $\sim 1600 \mathrm{~m}$ & $400 \sim 600 \mathrm{~m}$ \\
\hline Pulse rate & Up to $500,000 \mathrm{~Hz}$ & $35,000 \mathrm{~Hz}$ \\
\hline Beam divergence & $0.5 \mathrm{mrad}$ & $4.5 \mathrm{mrad}$ \\
\hline Field of view & $\pm 14^{\circ}$ front $/$ back, $\pm 20^{\circ}$ left/right \\
\hline Scan rate & Up to $70 \mathrm{~Hz}$ & Up to $35 \mathrm{~Hz}$ \\
\hline $\begin{array}{c}\text { Laser safety } \\
\text { standard }\end{array}$ & \multicolumn{2}{|c}{ Class IV } \\
\hline
\end{tabular}

Table 1. Specifications of Chiroptera II

\begin{tabular}{|c|c|}
\hline Flying height & $500 \mathrm{~m}$ \\
\hline Flying speed & $60 \mathrm{kt}$ \\
\hline Pulse rate & $470,000 \mathrm{~Hz}$ \\
\hline Scanning speed & $4,200 \mathrm{rpm}$ \\
\hline Points density & $31.5 \mathrm{point} / \mathrm{m}^{2}$ \\
\hline
\end{tabular}

Table 2. LiDAR surveying specifications in the preliminary experiment

\subsection{Experiment results}

Experiments results were evaluated following the general standard of operation specifications for Japanese public surveying (hereinafter referred as the Japanese general standard) established by the Ministry of Land, Infrastructure, Transport and Tourism of Japan. 
2.2.1 Point density: Point density acquired by ALS is usually evaluated by a data-missing rate in Japan. The datamissing rate is calculated as a ratio of meshes of which point density do not satisfy required point density. The data-missing rate is evaluated every $2 \mathrm{~km} \times 1.5 \mathrm{~km}$ rectangle. We verified with 1 point $/ 0.25 \mathrm{~m}^{2}$ (1 mesh: $\left.0.5 \mathrm{~m} \times 0.5 \mathrm{~m}\right), 4$ points $/ \mathrm{m}^{2}(1 \mathrm{mesh}:$ $1 \mathrm{~m} \times 1 \mathrm{~m})$, and 10 points $/ \mathrm{m}^{2}$ (1 mesh: $\left.1 \mathrm{~m} \times 1 \mathrm{~m}\right)$ since they are the most common required specification in Japan.

According to the Japanese general standard, if the mesh is smaller than $1 \mathrm{~m} \times 1 \mathrm{~m}$, data missing rate should be lower than 15 percent. Table 3 shows the results of the verification of point density. It is clear that the result with all three patterns of mesh size satisfied the required value.

\begin{tabular}{|c|c|c|c|c|}
\hline $\begin{array}{c}\text { Mesh } \\
\text { size }\end{array}$ & $\begin{array}{c}\text { Number of } \\
\text { points }\end{array}$ & $\begin{array}{c}\text { The mean } \\
\text { of } \\
\text { whole area }\end{array}$ & Min. & Max. \\
\hline $0.5 \mathrm{~m}$ & 1 & $0.01 \%$ & $0.00 \%$ & $0.03 \%$ \\
\hline $1 \mathrm{~m}$ & 4 & $0.01 \%$ & $0.00 \%$ & $0.02 \%$ \\
\hline $1 \mathrm{~m}$ & 10 & $0.01 \%$ & $0.00 \%$ & $0.03 \%$ \\
\hline
\end{tabular}

Table 3. Data missing rate in the preliminary experiment

2.2.2 Elevation verification accuracy of check points: We used six ground control points (GCPs) for adjustment of obtained point clouds. Four of them were located at four corners of the target area, while two of them were located around the centre of the target area. In addition, we set up 14 check points for evaluation of the quality of the obtained point clouds. Figure 4 shows the locations of the GCPs and check points.

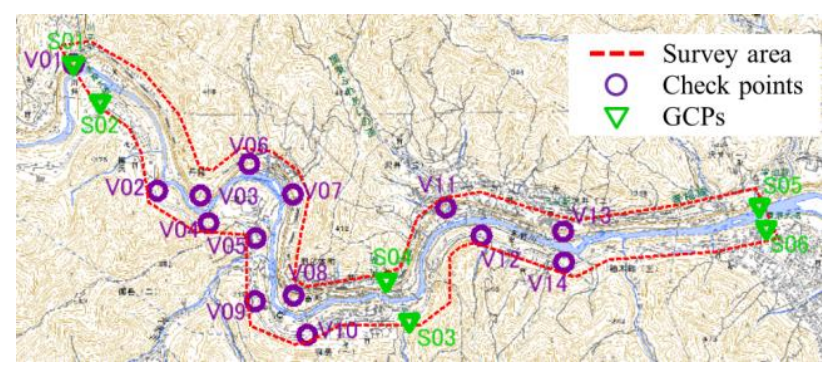

Figure 4 . GCPs and check points in the preliminary experiment

To evaluate observed elevation, we extracted observed points within $0.5 \mathrm{~m}$ radius from each check point and calculated a mean of the selected points as an observed elevation of the check point. We compared the elevation of each check point obtained by ALS with that obtained by GNSS surveying.

Table 4 shows statistics of differences of elevations of 14 check points between ALS and GNSS surveying. Table 4 shows that the elevation accuracy of checking points in ALS by a meandering flight would be nearly equal to that in ALS by a straight-line flight. The Japanese general standard defines that the absolute value of the mean of elevation differences of check points should be smaller than $0.25 \mathrm{~m}$ or the RMSE should be smaller than $0.25 \mathrm{~m}$. Table 4 indicates that both ALS by a meandering flight and ALS by a straight-line flight satisfied the requirement of the Japanese general standard.

\begin{tabular}{|c|c|c|c|c|}
\hline & Min.(m) & Max.(m) & Mean(m) & RMSE(m) \\
\hline $\begin{array}{c}\text { Meandering } \\
\text { flight }\end{array}$ & -0.080 & 0.078 & 0.004 & 0.040 \\
\hline $\begin{array}{c}\text { Straight line } \\
\text { flight }\end{array}$ & -0.097 & 0.106 & 0.004 & 0.057 \\
\hline
\end{tabular}

Table 4. Elevation verification accuracy of checking points in the preliminary experiment

2.2.3 Elevation verification accuracy between flying courses: We selected 10 examination points in 10 flat areas where adjacent flying courses were overlapped in order to evaluate elevation differences between flying courses. We extracted observed points within $0.5 \mathrm{~m}$ radius from each examination point and calculated a mean of the selected points as an elevation of the examination point.

Table 5 shows statistics of differences of elevations of 10 examination points between adjacent flying courses. According to the Japanese general standard, the absolute value of the mean of elevation differences of examination points between adjacent flying courses should be smaller than $0.30 \mathrm{~m}$. Table 5 indicates that the result of all flying courses satisfied the requirement of the Japanese general standard in both ALS by a straight-line flight and ALS by a meandering flight.

\begin{tabular}{|c|c|c|}
\hline \multirow{2}{*}{} & \multicolumn{2}{|c|}{$\Delta \mathrm{H}$} \\
\cline { 2 - 3 } & D1-D2 & D2-D3 \\
\hline Mean(m) & 0.027 & 0.028 \\
\hline Max.(m) & 0.055 & 0.059 \\
\hline Min.(m) & 0.004 & 0.001 \\
\hline RMSE(m) & 0.018 & 0.015 \\
\hline
\end{tabular}

Table 5. Elevation accuracy between adjacent flying courses in the preliminary experiment

\subsection{Discussion}

From the results of the preliminary experiment, we found the following points should be considered through ALS by a meandering flights. If we could satisfy those conditions, the improvement in data-accuracy of ALS by a meandering flight would be expected.

2.3.1 Flight planning: Figure 5 shows that the deviation of the actual trajectory from the planned flying course tends to be large around a sharp curve in the meandering flight. In proportion to the deviation of the trajectory the observed point density by ALS by the meandering flight tends to be uneven as Figure 6 shows. As for ALS by a straight-line flight, since the flight was planned so that overlapping ratio of adjacent flying courses should be $50 \%$, the observed point density became uniform. On the other hand, as for ALS by a meandering flight, since flight attitude control is difficult due to direction change of wind when aircraft enters the sharp curve nearly U-turn, it may have affected observed data.

Moreover, PDOP (position dilution of precision) value, which indicates degradation of position accuracy of GNSS, of a meandering flight becomes worse than that of a straight-line flight. The maximum value of PDOP was 2.0 in the straight-line flight, while that was 2.9 in the meandering flight. The cause of the degradation would be slower flight speed around a sharp 
curve in the meandering flight. The degradation of position accuracy of GNSS makes the accuracy of observed data worse. Therefore, it is preferable to divide a flying course into two or more flying courses so that all curves should be smaller than 90 degrees. Dividing a flying course makes point density uniform and secure GNSS and IMU accuracy.

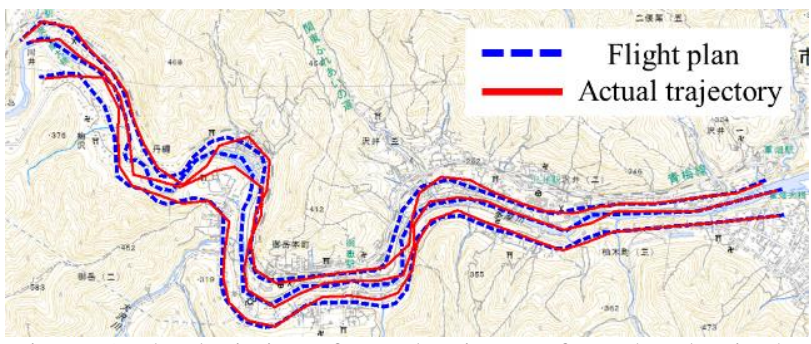

Figure 5. The deviation of actual trajectory from the plan in the preliminary experiment

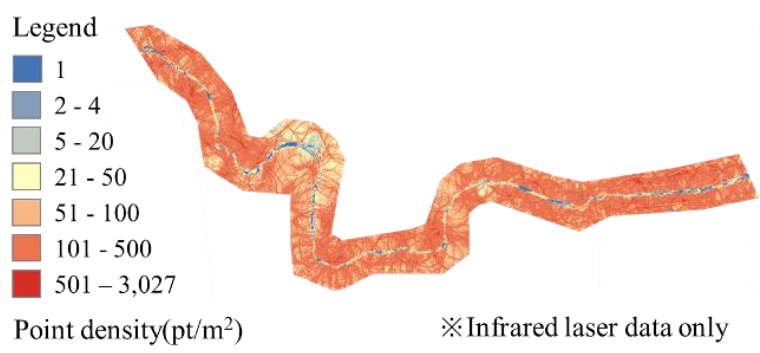

Figure 6. Point density of the preliminary experiment

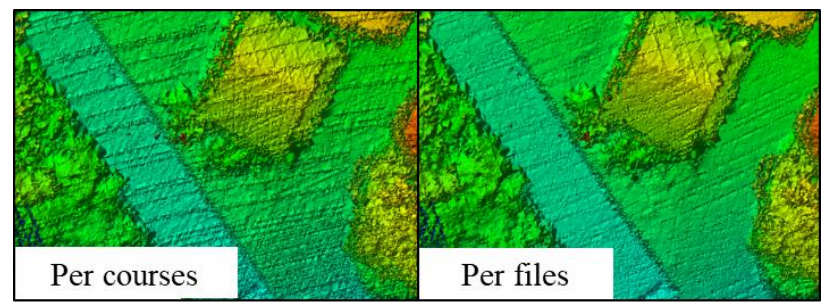

Figure 7. Results of adjustment between flying courses in the preliminary experiment

2.3.2 Adjustment between flying courses: In the case of ALS by a straight-line flight, adjustment is performed for each flying course in order to remove relative differences between adjacent flying courses. On the other hand, in the case of ALS of a meandering flight, as we mentioned above, the position of an aircraft varies within a flying course and the accuracy of measured position depends on its location within a flying course Differences between adjacent flying courses in a meandering flight cannot be completely eliminated with the same method as a straight-line flight as Figure 7a shows. Therefore, we decided that a flying course should be divided further. Our preprocessing software creates a point cloud file every softwarespecified data volume. Accordingly, we tried performing adjustment between point cloud files. In the preliminary experiment, a flying course was divided into approximately 100 files. Owing to this additional process each course does not have a large difference as Figure $7 b$ shows. Unfortunately, the additional processing would bring twice or three times work in comparison with course adjustment of ALS by a straight-line flight.
2.3.3 GCP allocation: In the ordinary ALS by a straight-line flight, we allocate GCPs at the four corners of a block or at an overlapped area. However, according to the findings mentioned in Subsection 2.3.1 and Subsection 2.3.2, difference between flying courses tends to be large around a shape curve in a meandering flight. Therefore, it would be effective to allocate check points at both ends of meandering flying courses and around a sharp curve in addition to ordinal GCPs. It helps to detect an area which possible have lower accuracy. If we could find an area with lower accuracy, we can adjust courses by using check points as additional GCPs. However, it means that more GCPs will be required in a more meandering area.

2.3.4 Surveying cost: In the preliminary experiment, the ALS by a straight-line flight had 10 flying courses and a total length was $90 \mathrm{~km}$, while the ALS by a meandering flight had 3 meandering flying courses and a total flight length was $50 \mathrm{~km}$. Since the length of a flying course became shorter, data acquisition time also reduced. The straight-line flight took 52 min for data acquisition. On the other hand, the meandering flight took $34 \mathrm{~min}$, which represents approximately a $2 / 3$ reduction compared with the straight-line flight.

The reduction of the flying courses helps reducing the number of turnings before entering a flying course, so it is effective in shortening data acquisition time. Even though the flying speed of meandering flight was slower (30kt) than straight-line flight (45kt), the data acquisition time becomes shorter. Therefore, the meandering flight data collection is efficient and can be useful in cases under the restricted data acquisition time.

Figure 8 shows the actual cost breakdown for each work flow of the ordinary ALS surveying. Since data acquisition cost accounts for $69 \%$ of the total cost. Therefore, the reduction of data acquisition cost by a meandering flight would be expected to produce the reduction of the total cost.

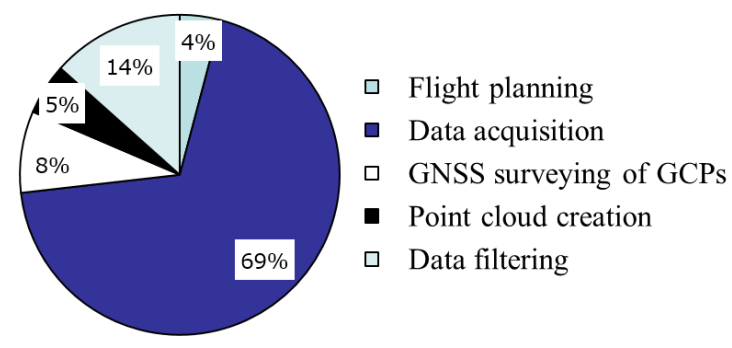

Figure 8. Ratio of a cost of each work in ordinary ALS surveying

\section{PRACTICAL EXPERIMENT}

\subsection{Outline of the practical experiment}

We conducted a practical experiment to investigate feasibility of adopting ALS by a meandering flight for Japanese public surveying. The practical experiment was conducted at the middle reaches of Ashida River, which is a Japan class A river, in Fuchu City, Hiroshima Prefecture. Figure 9 shows the target area. The Ashida River is surrounded by mountains and is a gentle mountainous area.

We used a Leica Chiroptera II as a sensor and an Aerospatiale AS350 as a platform in the practical experiment in the same way as the preliminary experiment. 

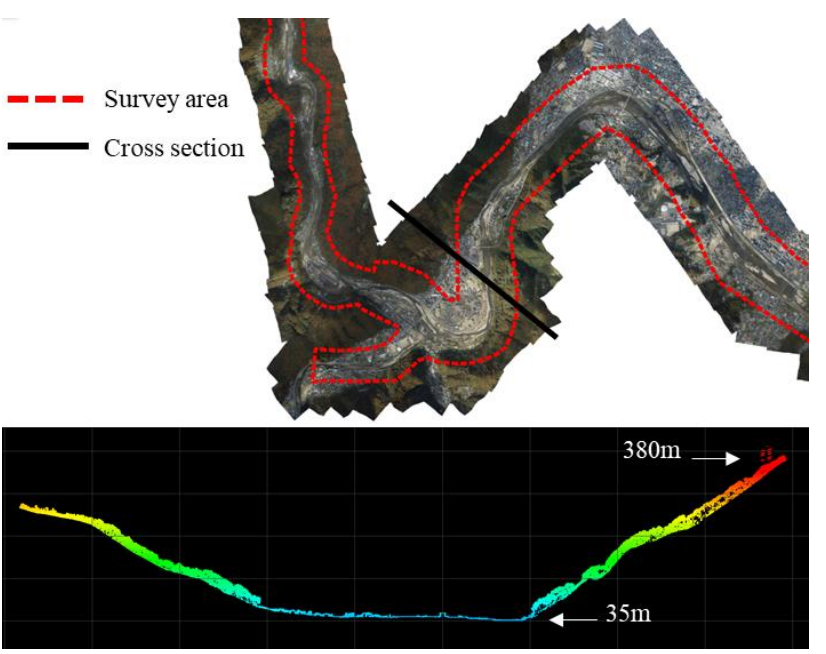

Figure 9. Target area of the practical experiment

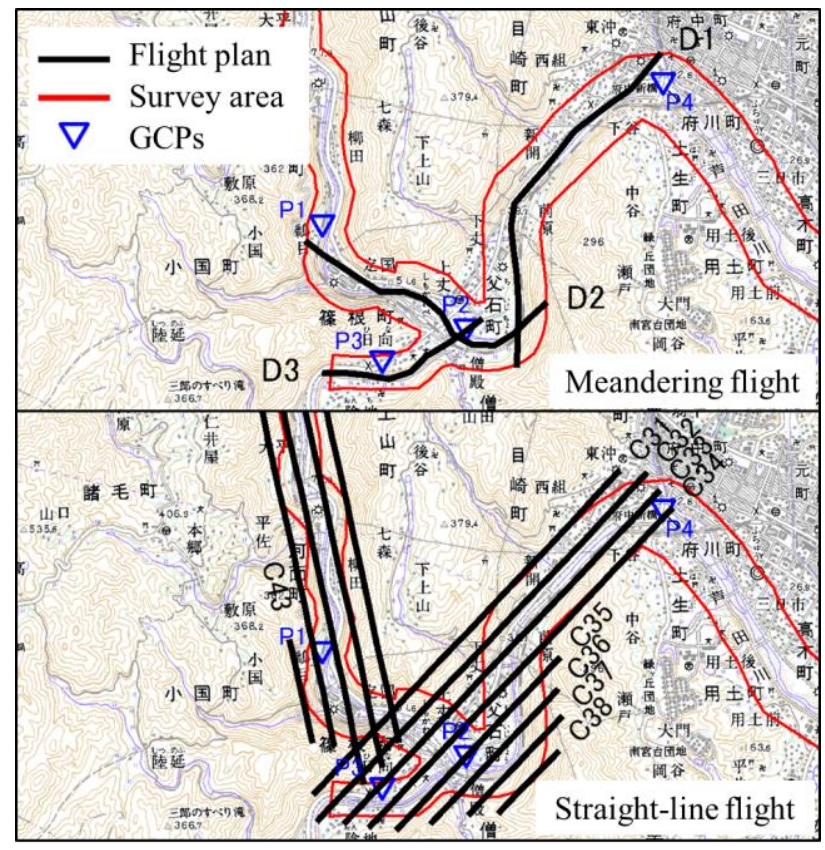

Figure 10. Flight plan of the practical experiment

We conducted ALS by a meandering flight and ALS by a straight-line flight on Nov. 15, 2018. Figure 10 shows the flight plans of both flights. Table 6 shows LiDAR surveying specifications. Based on the considerations of the results of the preliminary experiment as mentioned in Section 2.3, at the place where sharp curves are observed, the flight was divided into three flying courses where measurement was conducted.

\begin{tabular}{|c|c|}
\hline Flying height & $500 \mathrm{~m}$ \\
\hline Flying speed & $60 \mathrm{kt}$ \\
\hline Pulse rate & $150,000 \mathrm{~Hz}$ \\
\hline Scanning speed & $2,947 \mathrm{rpm}$ \\
\hline Points density & $10.5 \mathrm{point} / \mathrm{m}^{2}$ \\
\hline
\end{tabular}

Table 6. LiDAR surveying specifications in the practical experiment

\subsection{Results and discusssion}

We set up four GCPs for adjustment of obtained point cloud at both ends of each flying course in the same way as the preliminary experiment. Table 7 shows elevation accuracy of the adjustment. Table 7 indicates that the accuracy of ALS by a meandering flight would be nearly equal to that by a straightline flight. Furthermore, Table 7 indicates that ALS by a meandering flight would be able to be adopted for Japanese public surveying.

\begin{tabular}{|c|c|c|c|c|}
\hline & Min.(m) & Max.(m) & Mean(m) & RMSE(m) \\
\hline $\begin{array}{c}\text { Meandering } \\
\text { flight }\end{array}$ & -0.006 & 0.021 & 0.006 & 0.011 \\
\hline $\begin{array}{c}\text { Straight line } \\
\text { flight }\end{array}$ & -0.014 & 0.012 & -0.005 & 0.011 \\
\hline
\end{tabular}

Table 7. Elevation accuracy in the practical experiment

A meandering flight can reduce data acquisition time in comparison with a straight-line flight. The acquisition time of the 8 straight-line flying courses was 38 minutes, while that of 3 meandering flying courses was 14 minutes.

Moreover, although the deviation of the actual trajectory from the planned flying course and uneven point density observed were found in the preliminary experiment, these faults were improved through dividing flying courses as Figure 11 and Figure 12 show.

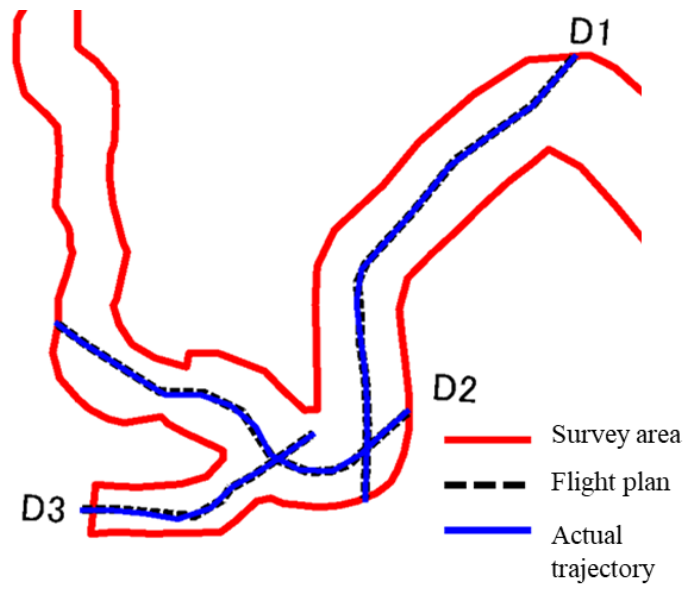

Figure 11. Deviation of actual trajectory from the flight plan of the practical experiment

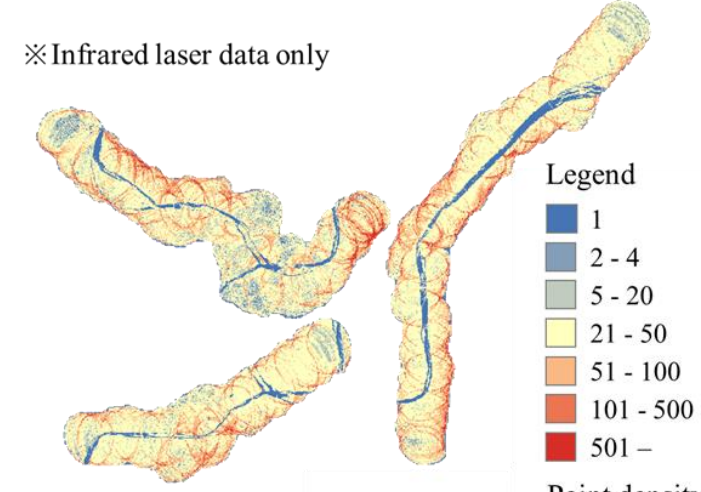

Point density $\left(\mathrm{pt} / \mathrm{m}^{2}\right)$

Figure 12. Point density in the practical experiment 


\section{CONCLUSION}

We conducted the preliminary experiment at the upper reaches of Tama River and practical experiment at the middle reaches of Ashida River in order to develop a new efficient ALS method by a meandering flight. The former was intended to investigate possibility of ALS by a meandering flight, and the latter was intended to investigate feasibility of adopting ALS by a meandering flight in Japanese public surveying.

We conclude that a meandering flight would be able to be adopted for Japanese public surveying by using the methods developed by us based on the results of the preliminary experiment.

As for measurement quality, the experiment results indicate that there would be some differences between flying courses that cannot be completely removed by adjustment in ALS by a meandering flight. However, the experimental results show that the accuracy of ALS by a meandering flight would be nearly equal to that by a straight-line flight, and satisfy the requirement of Japanese public surveying.

As for measuring cost, ALS by a meandering flight requires more work in GNSS surveying of GCPs and adjustment between flying courses than ALS by a straight-line flight. On the other hand, ALS by a meandering flight requires significantly less work in flight planning and data acquisition than ALS by a straight-line flight. From the point view of total cost, we consider that ALS by a meandering flight would be more efficient in total cost that ALS by a straight-line flight.

We summarized the characteristics of ALS by a meandering flight based on the experiment results. Table 8 shows the summary of the characteristics of ALS by a meandering flight in comparison with ALS by a straight-line flight.

Japan has many rivers meandering in narrow steep-walled valley. ALS by a straight-line flight would be unable to obtain data enough for disaster prevention in the surrounding of such meandering rivers. We expect that ALS by a meandering flight is a promising measure for disaster prevention in Japan. We are going to establish more efficient and more accurate ALS by a meandering flight by adopting some new methods dedicated to ALS by a meandering flight.

\begin{tabular}{|c|c|c|}
\hline & Quality & Cost \\
\hline Flight planning & N/A & Less \\
\hline Data acquisition & N/A & Less \\
\hline $\begin{array}{c}\text { GNSS surveying } \\
\text { of GCPs }\end{array}$ & N/A & More \\
\hline $\begin{array}{c}\text { Adjustment } \\
\text { between courses }\end{array}$ & Slightly lower & Nearly equal \\
\hline $\begin{array}{c}\text { Point cloud } \\
\text { creation }\end{array}$ & Nearly equal & Nearly equal \\
\hline Data filtering & Nearly equal & Less \\
\hline Total & $\begin{array}{c}\text { Slightly lower, } \\
\text { But allowable }\end{array}$ \\
\hline
\end{tabular}

Table 8. Characteristics of ALS by a meandering flight in comparison with ALS by a straight-line flight

\section{ACKNOWLEDGEMENTS}

The practical experiment at the middle reaches of Ashida River was conducted as a part of "Airborne laser scanning data collection for Ashida River" that was contracted with Fukuyama River and National Highway Office, Chugoku Regional Development Bureau, the Ministry of Land, Infrastructure, Transport and Tourism of Japan. The authors are grateful for their cooperation in the experiment and their permission of publishing the experiment results.

\section{REFFERENCES}

Hiramatsu, S., Ishida, K., Kanazawa, A., Gonda, Y., Sawa, Y., Tsutsumi, D., Nagayama, T., Fukuyama, T., Mantoku, M, Miike, T., Morishita, A., Yajima, K., Yamada, Y., 2017. Slope failure and subsequent debris flow occurrence on May 2017 at Iiyama, Nagano, Japan. Journal of the Japan Society of Erosion Control Engineering, 70(3), 41-50.

Yoshida, K., Maeno, S., Mano, K., Yamaguchi, K., Akoh, R., 2017. Accuracy validation of planar river bed survey using airborne laser bathymetry and examination of the improvement effect on river flow analysis. Journal of Japan society of civil engineers, SER. B1(Hydraulic Engineering), 73(4), 565-570. 